\title{
Toll-like receptor 9 promoter polymorphism is associated with decreased risk of Alzheimer's disease in Han Chinese
}

\author{
Ying-Li Wang ${ }^{1 \dagger}$, Meng-Shan Tan ${ }^{2 \dagger}$, Jin-Tai Yu ${ }^{1,2,3^{*}}$, Wei Zhang ${ }^{1}$, Nan Hu ${ }^{1}$, Hui-Fu Wang ${ }^{3}$, Teng Jiang ${ }^{3}$
} and Lan $\operatorname{Tan}^{1,2,3^{*}}$

\begin{abstract}
Background: Toll-like receptors (TLRs), as major innate immune mediators, may be involved in clearance of cerebral amyloid- $\beta$ (A $\beta$ ) deposits. Recently, a novel TLR9 signaling pathway has been uncovered, which is functionally associated with the immune inflammatory response and reducing $A \beta$ burden in Alzheimer's disease (AD) mice. Therefore, TLR9 might represent a reasonable functional candidate gene for AD.

Findings: Our study investigated 1,133 sporadic late-onset AD (LOAD) and 1,159 healthy controls matched for sex and age in a large Han Chinese population. One selected functional rs187084 polymorphism within the TLR9 gene was genotyped by polymerase chain reaction-ligase detection reaction in a case-control associated study. The TLR9 rs187084 variant homozygote GG was significantly associated with a decreased LOAD risk after adjusting for age, gender, and ApoE $\varepsilon 4$ status by logistic regression analysis $(P=0.035)$. Our result showed significant evidence of the interaction of ApoE $\varepsilon 4$ with rs 187084. When we further stratified our data by the ApoE $\varepsilon 4$ status, we detected significant differences in the genotype and allele distributions of rs 187084 between LOAD patients and controls in ApoE $\varepsilon 4$ carriers $(P<0.001, P=0.003$, respectively). Moreover, we examined TLR9 expression in peripheral blood monocytes by flow cytometry, and the GG genotype of the TLR9 rs187084 polymorphism was associated with a higher TLR9 expression than two other genotypes in LOAD patients.
\end{abstract}

Conclusion: Our findings support the hypothesis that the TLR9 polymorphism may modify LOAD risk in the Han Chinese population.

Keywords: Alzheimer's disease, Polymorphisms, TLR9, rs187084, Expression, Association study

\section{Background}

Alzheimer's disease (AD) is the most common form of dementia in the elderly, characterized by a slow but progressive loss of cognitive function and memory [1]. The cardinal pathological hallmark of $A D$ is amyloid- $\beta(A \beta)$ deposits in neuritic plaques and cerebral vessels [2] which are closely associated with inflammatory responses such as activated microglia in brain [3]. Increasing evidence indicates that the immune inflammatory mechanisms are not merely

\footnotetext{
*Correspondence: yu-jintai@163.com; dr.tanlan@163.com

${ }^{\dagger}$ Equal contributors

'Department of Neurology, Qingdao Municipal Hospital, School of Medicine, Qingdao University, Qingdao, China

${ }^{2}$ Department of Neurology, Qingdao Municipal Hospital, College of Medicine and Pharmaceutics, Ocean University of China, Qingdao, China

Full list of author information is available at the end of the article
}

bystanders in neurodegeneration but powerful pathogenetic forces in $\mathrm{AD}$ progression [4].

Toll-like receptors (TLRs) are a family of innate immune mediators that are expressed by a variety of immune and nonimmune cells [5]. There are at least 13 distinct TLR family members known in mammals, of which the pathogen specificities of 10 (TLR1-9 and 11) have been identified [6]. Like many other receptor families, TLRs act as heterodimers to add specificity to their recognition repertoire. Among them, TLR9 is localized to the endosomal-lysosome compartment where it can recognize unmethylated cytosine-guanosine $(\mathrm{CpG})$ DNA from internalized bacteria and viruses $[7,8]$. Unlike TLR2 and TLR4, TLR9 agonism did not aggravate $A \beta$-induced microglial activation in the immune response [9]. In addition, it has been demon- 
Table 1 Demographic and clinical characteristics of the study subjects

\begin{tabular}{|c|c|c|c|}
\hline & $A D(n=1,133)$ & Control $(n=1,159)$ & $P$-value \\
\hline Age at examination (years) (mean \pm SD) & $79.94 \pm 8.12$ & $74.48 \pm 6.29$ & \\
\hline Age at onset (years) (mean \pm SD) & $75.01 \pm 8.00$ & & $0.078^{\mathrm{a}}$ \\
\hline \multicolumn{4}{|l|}{ Gender, n (\%) } \\
\hline Male & $464(41.0)$ & $518(44.7)$ & \multirow[t]{2}{*}{0.070} \\
\hline Female & $669(59.0)$ & $641(55.3)$ & \\
\hline MMSE (mean $\pm S D)$ & $10.06 \pm 3.82$ & $28.26 \pm 1.08$ & $<0.001$ \\
\hline \multicolumn{4}{|l|}{ ApoE $\varepsilon 4$ status, $n$ (\%) } \\
\hline ApoE $\varepsilon 4$ carrier & $315(27.8)$ & $158(13.6)$ & \multirow[t]{2}{*}{$<0.001$} \\
\hline ApoE $\varepsilon 4$ noncarrier & $818(72.2)$ & $1,001(86.4)$ & \\
\hline
\end{tabular}

${ }^{a} P$ value was calculated with the age of onset for late-onset $A D$ and age at examination for controls. AD, Alzheimer's disease; ApoE $\varepsilon 4$, apolipoprotein $E$ ع4; MMSE, Mini-Mental State Examination.

strated that activation of TLRs with their specific ligands markedly boost uptake of $A \beta$, suggesting that TLR signaling pathways are involved in clearance of cerebral $A \beta$ deposits [10]. However, in mononuclear cells of AD patients, transcription of TLRs upon A $\beta$ stimulation is severely depressed [11]. More importantly, recent studies have pointed out that immune stimulation targeting TLR9 could dramatically attenuate $\mathrm{A} \beta$ neurotoxicity and reduce $\mathrm{A} \beta$ levels in in vitro and in vivo AD models [12]. Meanwhile, this reduction in amyloid was associated with cognitive improvement in AD mice [13]. Therefore, TLR9 might represent a reasonable functional candidate gene for AD.

The human TLR9 gene is located at $3 \mathrm{p} 21.3$. It has been demonstrated that polymorphisms in the TLR9 gene affect host susceptibility to a range of diseases, such as infection, immune inflammatory diseases, and cancers [14-17]. However, no studies have investigated the association between TLR9 polymorphisms and susceptibility to AD. In our current study, a functional variant of rs187084 located in the promoter region of TLR9 [18] was chosen. We hypothesize that the potentially functional rs187084 polymorphism may contribute to AD susceptibility. To test the hypothesis, we performed a case-control study including 1,133 LOAD cases and 1,159 healthy controls matched for sex and age in the Han Chinese population. Then, we compare the levels of TLR9 expression in peripheral blood monocytes of LOAD patients among the different rs187084 genotypes.

\section{Methods}

\section{Subjects}

Our study consisted of 1,133 LOAD (age at onset $\geq 65$ years) patients and 1,159 healthy controls matched for sex and age from the Department of Neurology of the Qingdao Municipal Hospital, and several other hospitals in Shandong Province. All of the above participants were unrelated Han Chinese in origin. A clinical diagnosis of probable AD was established according to the criteria of NINCDS-ADRDA [19]. No AD patient had a family history of dementia. The control group underwent neurological and medical examinations, which showed that they were free of any symptoms suggestive of cognitive decline. An informed consent to participate in this study was obtained from each subject or from a guardian, and the protocol of this study was approved by the Ethical Committee of Qingdao Municipal Hospital.

\section{Genotype analysis}

DNA was extracted from the peripheral blood leukocytes of patients and healthy controls using the Wizard genomic DNA purification kit (\#A1125; Promega, Madison, WI, USA). The polymorphism at position rs187084 on chromosome 3p21.3 was genotyped by polymerase chain reactionligase detection reaction (PCR-LDR) (TapMan Assay) on an ABI Prism 377 Sequence Detection System (Applied Biosystems, Foster City, CA, USA), with technical support from the Shanghai Genesky Biotechnology Company [20,21]. The primer sequences used for the PCR were:

Table 2 rs 187084 polymorphism association with Alzheimer's disease (AD) according to different genetic models

\begin{tabular}{llllll}
\hline SNP & Model $^{\mathbf{a}}$ & Wald & OR (95\% Cl) & $\boldsymbol{P}$ & $P$ for ApoE interaction \\
\hline rs187084 & D & 0.490 & $0.940(0.791$ to 1.118$)$ & 0.484 & 0.264 \\
& A & 2.538 & $0.906(0.801$ to 1.023$)$ & 0.111 & 0.009 \\
& R & 4.459 & $0.776(0.613$ to 0.982$)$ & 0.035 & $<0.001$
\end{tabular}

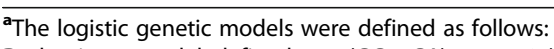

$D$, dominant model, defined as $1(G G+G A)$ versus $0(A A)$;

$A$, additive model, 2 (GG) versus $1(G A)$ versus $0(A A)$;

$R$, recessive model, $1(G G)$ versus $0(G A+A A)$.

$P<0.05$ was considered significant.

ApoE, apolipoprotein E $\varepsilon 4$; Cl: confidence interval; OR: odds ratio; SNP, single-nucleotide polymorphism. 
Table 3 Genotype and allele frequencies for rs187084 stratified by apolipoprotein E $\varepsilon 4$ (ApoE) status

\begin{tabular}{|c|c|c|c|c|c|c|c|c|c|}
\hline \multirow[t]{2}{*}{ rs187084 } & \multirow[t]{2}{*}{$\mathbf{n}$} & \multicolumn{3}{|c|}{ Genotype } & \multirow[t]{2}{*}{$P$} & \multicolumn{2}{|c|}{ Allele } & \multirow[t]{2}{*}{$P$} & \multirow[t]{2}{*}{ OR $(95 \% \mathrm{Cl})$} \\
\hline & & GG (\%) & GA (\%) & AA (\%) & & G (\%) & $A(\%)$ & & \\
\hline$A D$ & 1,133 & $150(13.2)$ & $557(49.2)$ & $426(37.6)$ & 0.100 & $857(37.8)$ & $1,409(62.6)$ & 0.076 & $0.898(0.798$ to 1.011$)$ \\
\hline Control & 1,159 & $190(16.4)$ & $556(48.0)$ & $413(35.6)$ & & $936(40.4)$ & $1,382(59.6)$ & & \\
\hline \multicolumn{10}{|c|}{ ApoE $\varepsilon 4$ carriers } \\
\hline$A D$ & 315 & $30(9.5)$ & $156(49.5)$ & $129(40.1)$ & $<0.001$ & $216(34.3)$ & $414(65.7)$ & 0.003 & 0.656 (0.498 to 0.865$)$ \\
\hline Control & 158 & $38(24.1)$ & $64(40.5)$ & $56(35.4)$ & & $140(44.3)$ & $176(55.7)$ & & \\
\hline \multicolumn{10}{|c|}{ ApoE $\varepsilon 4$ noncarriers } \\
\hline$A D$ & 818 & $120(14.7)$ & $401(49.0)$ & $297(36.3)$ & 0.936 & $641(39.2)$ & 995 (60.8) & 0.722 & 0.976 (0.854 to 1.116$)$ \\
\hline Control & 1,001 & $152(15.2)$ & 492 (49.2) & $357(35.7)$ & & 796 (39.8) & $1,206(60.2)$ & & \\
\hline
\end{tabular}

$\mathrm{AD}$, Alzheimer's disease; $\mathrm{ApoE} \varepsilon 4$, apolipoprotein $\mathrm{E} \varepsilon 4$; $\mathrm{Cl}$, confidence interval; OR, odds ratio.

forward: 5'-CGTCTTATTCCCCTGCTGGAATG-3'; reverse: 5'-CCTCCCAGCAGCAACAATTCAT-3'. Data analysis was achieved using GeneMapper Software v4.0 (Applied Biosystems, Foster City, CA, USA). Results of the PCR-LDR method corresponded with the results of sequencing for the randomly selected DNA samples from each genotype. ApoE was also genotyped by the PCR-LDR method.

\section{TLR9 expression analysis by flow cytometry}

Venous blood was obtained from 60 LOAD patients (20 randomly selected cases from each genotype). Whole blood cells collected in sodium heparin tubes were stained with fluorescein isothiocyanate (FITC)-conjugated anti-human CD14 (BD Biosciences, San Jose, CA, USA) to identify the monocyte population. After being washed, the cells were permeabilized, and then stained with anti-human TLR9 antibody (eBioscience, San Diego, CA, USA). The isotypematched IgG2a antibody was used as control. After being washed again, cells were incubated with phycoerythrinconjugated secondary antibody. Expression of TLR9 was gated and analyzed by flow cytometry (Beckman Coulter, Fullerton, CA, USA) as mean fluorescence intensity (MFI) with regard to isotype control signal. The data were calculated with Cell Quest Pro Software (Becton, Dickinson and Company, USA).

\section{Statistical analysis}

Hardy-Weinbery equilibrium (HWE) was tested with the $\chi^{2}$ test to calculate genotype and allele distribution. Statistical differences between $\mathrm{AD}$ cases and control subjects were also tested when we stratified our data by ApoE $\varepsilon 4$ status. Differences in the characteristics for our subjects were examined using the Student $t$-test or the $\chi^{2}$ test. Odds ratio (OR) and 95\% confidence intervals (CIs) were tested using logistic regression models after adjustment for sex, age, and ApoE \&4 status under various genetic models that were defined as 1 (GG + GA) versus 0 (AA) for dominant, 2 (GG) versus 1 (GA) versus 0 (AA) for additive, and $1(\mathrm{GG})$ versus $0(\mathrm{GA}+\mathrm{AA})$ for recessive. All statistical analyses were performed by IBM SSPS statistics 19.0 (IBM
Company, USA). The statistical power of the study was calculated by STPLAN43 software. The level of significance for all statistical tests was defined as $P<0.05$.

\section{Results}

The distribution of the TLR9 (rs187084) was in HWE for both $\mathrm{AD}$ patients and controls $(P>0.05)$. Allele and genotype frequencies of rs187084 in our control group were consistent with the $\mathrm{CHB}$ (Han Chinese in Beijing) genotype data in the HapMap database. Demographic and clinical characteristics of the participants are shown in Table 1 . There were no differences for gender $(P=$ $0.070)$ and age $(P=0.078)$ between $\mathrm{AD}$ and controls. We found significantly lower Mini-Mental State Examination (MMSE) scores in LOAD patients compared to the

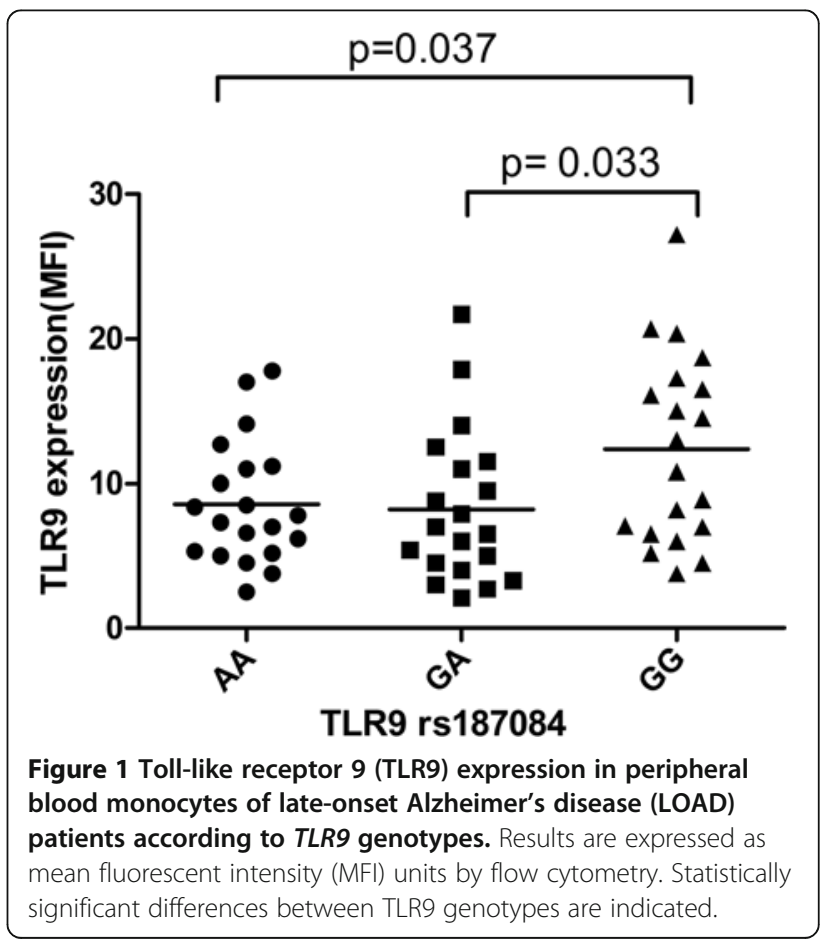


controls $(P<0.001)$. As expected, the ApoE $\varepsilon 4$ allele frequency was also significantly different between $\mathrm{AD}$ patients and controls $(P<0.001)$.

We evaluated single-nucleotide polymorphism (SNP) rs187084 effects under different models using logistic regression adjusting for age, gender, and ApoE $\varepsilon 4$ status. The rs187084 was found to significantly decrease the risk of developing LOAD in a recessive model $(\mathrm{OR}=0.776$, $95 \% \mathrm{CI}=0.613$ to 0.982 ), but not in dominant or additive models. Besides, an interaction between rs187084 polymorphism and ApoE was also observed in different genetic models (Table 2). When we further stratified our data according to ApoE $\varepsilon 4$ status, we detected significant differences in the genotype and allele distributions of rs187084 between LOAD patients and controls in ApoE $\varepsilon 4$ carriers $(P<0.001, P=0.003$, respectively); and the rs187084 minor G-allele significantly decreased the risk of LOAD (OR $=0.656,95 \%$ CI: 0.498 to 0.865 ). However, no significant frequency differences between $\mathrm{AD}$ and controls at allelic and genotype levels were observed in the total sample or in ApoE \&4 noncarriers (Table 3).

We further compared TLR9 levels in peripheral blood monocytes of LOAD patients among the different rs187084 genotypes. Our results showed that the GG genotype of the TLR9 rs187084 polymorphism was associated with a higher TLR9 expression than two other genotypes in LOAD patients (Figure 1).

\section{Discussion}

To the best of our knowledge, this is the first study to evaluate whether the TLR9 rs187084 polymorphism could influence susceptibility to LOAD in a large Han Chinese population. Logistic regression analyses showed that the rs187084 variant homozygote GG was associated with a significantly decreased LOAD risk $(\mathrm{OR}=$ $0.776,95 \% \mathrm{CI}=0.613$ to 0.982 ) in the recessive genetic model. Moreover, rs187084 showed a significant ApoE interaction. After stratifying our data by ApoE $\varepsilon 4$ status, we detected significant differences in the genotype and allele distributions of rs187084 between LOAD patients and controls in ApoE 84 carriers. The minor G allele was revealed to be associated with a decreased risk of LOAD. These findings indicate that the $G$ allele of rs187084 is the protective allele against the development of LOAD. More importantly, the GG genotype of TLR9 rs187084 polymorphism was associated with a higher TLR9 expression than two other genotypes in LOAD patients.

The TLR9 rs187084 is a potentially functional variant located in the promoter region [18] which may regulate the TLR9 transcript levels and protein function. Several studies have investigated the effect of rs187084 polymorphism on human diseases, such as rheumatoid arthritis [14], systemic lupus erythematosus [22], symptomatic malaria
[23], Graves' ophthalmopathy [24], and cervical cancer [17]. In the current study, we found that the rs 187084 variant within TLR9 affected susceptibility to LOAD in a large Han Chinese population. The minor $G$ allele significantly decreased the risk of LOAD, and GG genotype upregulated TLR9 expression in peripheral blood monocytes of LOAD patients, demonstrating that functionality of the rs187084 polymorphism could change TLR9 expression. Considering the key role of TLR9 in clearance of cerebral $A \beta$ in $A D$ progression [13], this functional variant might play a protective role in AD by increasing $A \beta$ clearance. In-depth studies are greatly needed to confirm the functionality of the rs187084 polymorphism in the brain, and elucidate its detailed role in AD pathogenesis. In addition, only one selected SNP within the TLR9 gene was genotyped in our study. Future comprehensive investigation of the association between other polymorphisms in TLR9 and $\mathrm{AD}$ susceptibility is also warranted.

\section{Conclusion}

Our study demonstrated an association between TLR9 rs187084 polymorphism and LOAD risk. The G allele was revealed to be a protective factor for the LOAD in a Han Chinese population. However, it remains unknown whether it is applicable to other ethnic groups. Different populations and larger sample studies are necessary to validate our findings and further clarify the possible role of TLR9 in LOAD.

\section{Abbreviations}

Aß: Amyloid- $\beta$; AD: Alzheimer's disease; APP: Amyloid precursor protein; ApoE: Apolipoprotein E; CHB: Han Chinese in Beijing; Cl: Confidence interval; CNS: Central nervous system; FITC: Fluorescein isothiocyanate; HWE: HardyWeinbery equilibrium; LOAD: Late-onset Alzheimer's disease; MFI: Mean

fluorescence intensity; MMSE: Mini-Mental State Examination; OR: Odds ratio; PCRLDR: Polymerase chain reaction-ligase detection reaction; TLR: Toll-like receptors.

Competing interests

The authors declare they have no competing interests.

\section{Authors' contributions}

YLW, MST, and JTY were the main researchers in this study, and contributed to writing the manuscript. YLW, MST, JTY, WZ, NH, HFW, TJ, and LT were involved in collecting the blood samples and clinical data. YLW, MST, JTY and LT planned the study, wrote the protocol, were involved in the genetic and clinical aspects of data analyses, and revised the manuscript. All authors read and approved the final manuscript for publication.

\section{Authors' information}

Ying-Li Wang and Meng-Shan Tan are co-first authors.

\section{Acknowledgements}

We are grateful to all of the subjects who kindly agreed to participate in this study. This work was supported by grants from the National Natural Science Foundation of China $(81000544,81171209)$ and the Shandong Provincial Natural Science Foundation, China (ZR2010HQ004, ZR2011HZ001).

\section{Author details}

'Department of Neurology, Qingdao Municipal Hospital, School of Medicine, Qingdao University, Qingdao, China. ²Department of Neurology, Qingdao Municipal Hospital, College of Medicine and Pharmaceutics, Ocean University of China, Qingdao, China. ${ }^{3}$ Department of Neurology, Qingdao Municipal Hospital, Nanjing Medical University, Qingdao, China. 
Received: 5 June 2013 Accepted: 15 August 2013

Published: 20 August 2013

\section{References}

1. Ballard C, Gauthier S, Corbett A, Brayne C, Aarsland D, Jones E: Alzheimer's disease. Lancet 2011, 377:1019-1031.

2. Hardy J, Selkoe DJ: The amyloid hypothesis of Alzheimer's disease: progress and problems on the road to therapeutics. Science 2002, 297:353-356.

3. Prinz M, Priller J, Sisodia SS, Ransohoff RM: Heterogeneity of CNS myeloid cells and their roles in neurodegeneration. Nature neuroscience 2011, 14:1227-1235.

4. Sastre M, Richardson JC, Gentleman SM, Brooks DJ: Inflammatory risk factors and pathologies associated with Alzheimer's disease. Current Alzheimer research 2011, 8:132-141.

5. Crack PJ, Bray PJ: Toll-like receptors in the brain and their potential roles in neuropathology. Immunology and cell biology 2007, 85:476-480.

6. Kawai T, Akira S: The role of pattern-recognition receptors in innate immunity: update on Toll-like receptors. Nat Immunol 2010, 11:373-384.

7. Latz E, Schoenemeyer A, Visintin A, Fitzgerald KA, Monks BG, Knetter CF, Lien E, Nilsen NJ, Espevik T, Golenbock DT: TLR9 signals after translocating from the ER to CpG DNA in the lysosome. Nat Immunol 2004, 5:190-198.

8. Hemmi H, Takeuchi O, Kawai T, Kaisho T, Sato S, Sanjo H, Matsumoto M, Hoshino K, Wagner H, Takeda K, Akira S: A toll-like receptor recognizes bacterial DNA. Nature 2000, 408:740-745.

9. Lotz M, Ebert S, Esselmann H, lliev Al, Prinz M, Wiazewicz N, Wiltfang J, Gerber J, Nau R: Amyloid beta peptide 1-40 enhances the action of toll-like receptor- 2 and -4 agonists but antagonizes Toll-like receptor-9-induced inflammation in primary mouse microglial cell cultures. Journal of neurochemistry 2005, 94:289-298.

10. Tahara K, Kim HD, Jin JJ, Maxwell JA, Li L, Fukuchi K: Role of toll-like receptor signaling in Abeta uptake and clearance. Brain 2006, 129:3006-3019.

11. Fiala M, Liu PT, Espinosa-Jeffrey A, Rosenthal MJ, Bernard G, Ringman JM, Sayre J, Zhang L, Zaghi J, Dejbakhsh S, et al: Innate immunity and transcription of MGAT-III and toll-like receptors in Alzheimer's disease patients are improved by bisdemethoxycurcumin. Proc Natl Acad Sci USA 2007, 104:12849-12854.

12. Doi Y, Mizuno T, Maki Y, Jin S, Mizoguchi H, Ikeyama M, Doi M, Michikawa M, Takeuchi H, Suzumura A: Microglia activated with the toll-like receptor 9 ligand CpG attenuate oligomeric amyloid beta neurotoxicity in in vitro and in vivo models of Alzheimer's disease. Am J Pathol 2009, 175:2121-2132.

13. Scholtzova H, Kascsak RJ, Bates KA, Boutajangout A, Kerr DJ, Meeker HC, Mehta PD, Spinner DS, Wisniewski T: Induction of toll-like receptor 9 signaling as a method for ameliorating Alzheimer's disease-related pathology. J Neurosci 2009, 29:1846-1854.

14. Lee $\mathrm{YH}$, Bae SC, Song GG: Meta-analysis demonstrates association between TLR polymorphisms and rheumatoid arthritis. Genetics and molecular research: GMR 2013, 12:328-334.

15. Royse KE, Kempf MC, McGwin G Jr, Wilson CM, Tang J, Shrestha S: Toll-like receptor gene variants associated with bacterial vaginosis among HIV-1 infected adolescents. Journal of reproductive immunology 2012, 96:84-89.

16. Piotrowski $P$, Lianeri $M$, Wudarski $M$, Olesinska $M$, Jagodzinski PP: Contribution of toll-like receptor 9 gene single-nucleotide polymorphism to systemic lupus erythematosus. Rheumatol Int 2013, 33:1121-1125.

17. Chen X, Wang S, Liu L, Chen Z, Qiang F, Kan Y, Shen Y, Wu J, Shen H, Hu Z: A genetic variant in the promoter region of toll-like receptor 9 and cervical cancer susceptibility. DNA Cell Biol 2012, 31:766-771.

18. Hamann L, Glaeser C, Hamprecht A, Gross M, Gomma A, Schumann RR: Toll-like receptor (TLR)-9 promotor polymorphisms and atherosclerosis. Clin Chim Acta 2006, 364:303-307.

19. McKhann G, Drachman D, Folstein M, Katzman R, Price D, Stadlan EM: Clinical diagnosis of Alzheimer's disease: report of the NINCDS-ADRDA Work Group under the auspices of Department of Health and Human Services Task Force on Alzheimer's Disease. Neurology 1984, 34:939-944.

20. Xiao Z, Xiao J, Jiang Y, Zhang S, Yu M, Zhao J, Wei D, Cao H: A novel method based on ligase detection reaction for low abundant YIDD mutants detection in hepatitis B virus. Hepatol Res 2006, 34:150-155.

21. Favis R, Day JP, Gerry NP, Phelan C, Narod S, Barany F: Universal DNA array detection of small insertions and deletions in BRCA1 and BRCA2. Nat Biotechnol 2000, 18:561-564.

22. Huang CM, Huang PH, Chen CL, Lin YJ, Tsai CH, Huang WL, Tsai FJ: Association of toll-like receptor 9 gene polymorphism in Chinese patients with systemic lupus erythematosus in Taiwan. Rheumatol Int 2012, 32:2105-2109.

23. Omar AH, Yasunami M, Yamazaki A, Shibata H, Ofori MF, Akanmori BD, Shuaibu MN, Kikuchi M, Hirayama K: Toll-like receptor 9 (TLR9) polymorphism associated with symptomatic malaria: a cohort study. Malaria journal 2012, 11:168.

24. Liao WL, Chen RH, Lin HJ, Liu YH, Chen WC, Tsai Y, Wan L, Tsai FJ: Toll-like receptor gene polymorphisms are associated with susceptibility to Graves' ophthalmopathy in Taiwan males. BMC medical genetics 2010, 11:154.

doi:10.1186/1742-2094-10-101

Cite this article as: Wang et al:: Toll-like receptor 9 promoter polymorphism is associated with decreased risk of Alzheimer's disease in Han Chinese. Journal of Neuroinflammation 2013 10:101.

\section{Submit your next manuscript to BioMed Central and take full advantage of:}

- Convenient online submission

- Thorough peer review

- No space constraints or color figure charges

- Immediate publication on acceptance

- Inclusion in PubMed, CAS, Scopus and Google Scholar

- Research which is freely available for redistribution

Submit your manuscript at www.biomedcentral.com/submit
C Biomed Central 